Pre-publication accepted version:

Charlotte Jane Whiffin, Caroline Ellis-Hill, Christopher Bailey, Nikki Jarrett \& Peter J. Hutchinson (2017): We are not the same people we used to be: An exploration of family biographical narratives and identity change following traumatic brain injury, Neuropsychological Rehabilitation, DOI: 10.1080/09602011.2017.1387577

To link to this article: http://dx.doi.org/10.1080/09602011.2017.1387577

We are not the same people we used to be: an exploration of family biographical narratives and identity change following Traumatic Brain Injury.

1. Charlotte Jane Whiffin (corresponding author)

Senior Lecturer in Nursing, College of Health and Social Care, University of Derby, England

University of Derby, Kedleston Road, Derby, DE22 1GB, UK

Tel: 01332593882 Email: c.whiffin@derby.ac.uk

ORCID number: 0000-0002-9767-2123

2. Caroline Ellis-Hill

Senior Lecturer, Faculty of Health and Social Sciences, Bournemouth University, England

Royal London House, Lansdowne Campus, Bournemouth University, Christchurch Road, Bournemouth, BHI 3LT, UK

Tel: 01202962173 Email: cehill@bournemouth.ac.uk

ORCID number 0000-0002-3593-5514

3. Christopher Bailey

Associate Professor, School of Health Sciences, The University of Nottingham, England 
The University of Nottingham, Queen’s Medical Centre, Nottingham, NG7 2HA

Tel: +44 (0) 1158230917 Email: Christopher.Bailey@nottingham.ac.uk

ORCID: 0000-0002-7528-6264

\section{Nikki Jarrett}

Lecturer in Health Sciences, Faculty of Health Sciences, University of Southampton

Faculty of Health Sciences, University of Southampton, Highfield, Southampton, SO17 1BJ, UK

Tel: (023) $80597954 \quad$ email: N.Jarrett@soton.ac.uk

ORCID Number: 0000-0003-2513-8113

\section{Peter Hutchinson}

Professor of Neurosurgery/NIHR Research Professor Department of Clinical Neurosciences, University of Cambridge, UK

Box 167 Academic Division of Neurosurgery, Addenbrooke’s Hospital, Cambridge, CB2 2QQ, UK.

Tel: +441223336946_email: pjah2@cam.ac.uk

ORCID number 0000-0002-2796-1835 


\section{ABSTRACT}

Subjective changes are increasingly recognised as important in recovery and rehabilitation following traumatic brain injury. Accumulation of subjective changes over time has led many to examine the question of 'continuity of self' post-injury. Vacillation between feeling the same and different is common and often at odds with the medical narrative preparing families for permanent change. This position of ambiguity was examined in a qualitative narrative study. The aim of this paper is to describe the narrative structures used by uninjured members of a family to understand change. These changes relate primarily, to their perspective of whether and how the injured person had changed, but also secondarily to whether and why they themselves felt they had changed in the first year post-injury. Nine uninjured family members from three families took part in three unstructured interviews during the first twelve months post-injury. In-depth narrative analysis showed family members used biographical attendance; biographical disruption; biographical continuity and biographical reconstruction to understand change. Drawing on these findings it is argued that concentrating on a narrative of change is too limiting and that engaging in biographical narratives may help humanise care provided to injured individuals and their families. Implications for research and practice are discussed.

\section{KEYWORDS:}

Traumatic Brain Injury; Family; Rehabilitation; Identity; Change

Funding details: No funding to declare

Disclosure statement: No conflict of interest

Word Counts: Abstract: 198

Main Text: 6770 


\section{INTRODUCTION}

In England and Wales 1.4 million people attend emergency departments with head injuries each year and of these approximately 200,000 people are admitted to hospital (National Institute for Care and Clinical Excellence, 2014). Traumatic brain injuries (TBI) cause significant losses to individuals, families and communities and neurotrauma is identified as a global public health concern (World Health Organisation, 2017). Physical, psychological, and emotional sequelae post-injury are common (Kreutzer, Mills, \& Marwitz, 2016; Ownsworth \& Haslam, 2016) and life changing psychoemotional responses extend well beyond physical recovery (Muenchberger, Kendall, \& Neal, 2008). Injured persons and their families can expect a reduction in social participation and an increase in social isolation and emotional distress (Couchman, McMahon, Kelly, \& Ponsford, 2014). According to Bowen et al., (2009) there are both direct and indirect consequences of TBI. Direct consequences arise from deficits in cognitive, emotional, social, and behavioural functioning. Indirect effects stem from the negative responses of significant others (Bowen et al., 2009).

\section{Impact of TBI on uninjured family members in adult populations}

Studies have shown that those who care for adults with TBI are at a higher risk of developing psychological symptoms of depression, stress and anxiety (Harris, Godfrey, Partridge, \& Knight, 2001; Perlesz, Kinsella, \& Crowe, 2000; Riley, 2007; Rivera, Elliott, Berry, \& Grant, 2008). Historically, the stress and burden that TBI has on primary carers has dominated the research literature (Degeneffe, 2001). The presence of neurobehavioural sequelae in the injured adult post-TBI reliably predicts carer outcomes (Blake, 2008; Connolly \& O’Dowd, 2001; Harris et al., 2001; Jackson, Turner-Stokes, Murray, Leese, \& McPherson, 2009; Perlesz et al., 2000; Ponsford, Olver, Ponsford, \& Nelms, 2003; Wells, Dywan, \& Dumas, 2005). These studies tell us 
that it is not the physical demands of caring but trying to live with changes in behaviour, cognition and personality that generate the greatest sense of burden.

Where a family has been supported by two spouses and one sustains a head injury, the other must assume sole responsibility (Zeigler, 1999). Therefore spouses are generally considered to be at greater risk of stress and burden than parents (Gervasio \& Kreutzer, 1997). The loss of a supportive partnership has been cited as one reason for this (Perlesz et al., 2000) in addition to a loss of intimacy and change in role from equal partner to something more akin to a parent (Gill, Sander, Robins, Mazzei, \& Struchen, 2011; Hammond, Davis, Whiteside, Philbrick, \& Hirsch, 2011). Therefore TBI is habitually referred to as a factor that threatens marital and family stability (Gosling \& Oddy, 1999). Despite this Kreutzer, Marwitz, Hsu, Williams, \& Riddick (2007) identified several factors that reliably predict marital stability in TBI populations. These included being older, married for longer prior to the injury, having milder injuries and being victims of non-violent crimes.

Sibling bonds are important to individuals and families as these relationships are frequently the longest a person will ever have (Degeneffe \& Lynch, 2006). The longterm nature of TBI means that siblings often take over caregiving responsibilities once parents can no longer manage or have passed away (Orsillo, McCaffrey, \& Fisher, 1993). Although siblings are more likely to provide affective rather than instrumental support following TBI siblings still reported higher rates of depression than would be expected of the general population (Degeneffe \& Burcham, 2008; Degeneffe \& Lynch, 2006). Sibling concerns related to changes in their personal relationship with the injured person, the altered function and structure of the family and their long-term responsibilities (Degeneffe \& Lee, 2010; Degeneffe \& Olney, 2008, 2010; Gill \& Wells, 2000). 
Butera-Prinzi and Perlesz (2004) and Harris and Stuart (2006) investigated the experiences of children who had a parent with a TBI. Children were worried and anxious about the future of their family; they feared family disintegration (Butera-Prinzi \& Perlesz, 2004) and expressed concern for the uninjured mother's suffering (Harris \& Stuart, 2006). Children whose father was injured expressed loss and grief with past images of their father held in high regard and these were in stark contrast to how they perceived their father post-injury (Butera-Prinzi \& Perlesz, 2004). In addition, KiefferKristensen, Teasdale, and Bilenberg, (2011) identified post-traumatic stress symptoms in children with brain injured parents. The findings of this study exemplify the vulnerability and support needs of this group.

\section{Family context in TBI}

Family functioning has emerged as a key variable post-TBI. Unhealthy family functioning has been found to correlate with increased strain and depression and reduced life satisfaction for both injured and non-injured family members (Anderson, Parmenter, \& Mok, 2002; Carnes \& Quinn, 2005; Gan, Campbell, Gemeinhardt, \& McFadden, 2006; Nabors, Seacat, \& Rosenthal, 2002). The Resilience Model of Family Stress, Adjustment and Adaptation (McCubin \& McCubin, 1991) hypothesises that a positive family schema (i.e. their beliefs, values, goals and expectations) will predict effective family functioning. This hypothesis was supported in Kosciulek’s (1997) study of primary carers and concluded manageability and meaningfulness were positively correlated to family functioning. In addition, there is increasing recognition that healthy family functioning is also related to better rehabilitation outcomes for the injured person (Sady et al., 2010; Sander et al., 2002, 2003).

In the wake of TBI, family relationships, lifestyles and quality of life may change both immediately and in the long term. These changes can threaten the 
equilibrium of the family system (Verhaeghe, Defloor, \& Grypdonck, 2005).

Ownsworth and Haslam (2016) have highlighted that, 'It is well recognised that brain injury can lead to significant loss and change in social relationships, and it is only when we understand how central they are to self-definition, that we can start to understand why such loss affects people so deeply' (p26). It has been argued that understanding the family context can help us to understand further how families adjust, cope and adapt post-TBI (Jumisko, Lexell, \& Soderberg, 2007; Whiffin, Bailey, EllisHill, Jarrett, \& Hutchinson, 2015; Yeates, Henwood, Gracey, \& Evans, 2007). Furthermore, Couchman et al. (2014) concluded that resolution of self-identity for the injured person was central to individual and family functioning. Therefore, the multiple contexts of individual family systems need to be explored to understand this further.

\section{Change in identity}

Subjective experiential changes are increasingly being recognised as important in understanding recovery and rehabilitation following TBI (Abrahamson, Jensen, Springett, \& Sakel, 2016; Couchman et al., 2014; Gracey et al., 2008; Muenchberger et al., 2008; Nochi, 1998; Ownsworth \& Haslam, 2016). Holloway and Freshwater (2007) argue that in the presence of trauma and illness what had been assumed about our lives and our perception of the future shifts or alters completely: 'individuals find themselves in a process of deconstructing and reconstructing [their] identity’ (p706).

By building on the concept of illness narratives by Bury (1982), Ellis-Hill, Payne, \& Ward (2008) argue that acquired disability should not just be seen as a time of 'loss'. Instead, it should be seen as a time of transition which may include losses but will include gains as well as aspects that do not change at all. 
Two literature reviews called for a more in-depth understanding of the process and patterns of family adaptation following TBI (Perlesz, Kinsella, \& Crowe, 1999; Verhaeghe et al., 2005) and studies by Jumisko, Lexell, and Soderberg (2007) and Yeates, Henwood, Gracey, and Evans (2007) have shown progress has been made to achieve this more multi-dimensional view of the family experience. However, now there is increasing interest in a more holistic understanding of change post-injury and how family centred approaches can complement rehabilitation (Foster et al., 2012). This paper continues this dialogue by examining how identifying the narrative structures used by uninjured family members contributes to understanding loss and change following TBI.

\section{AIM}

This paper reports data from a larger study that investigated the effect of TBI on the uninjured members of a family in the first year following injury. The full findings of this study are reported elsewhere (see Whiffin, 2012) and an exploration of how family members talked about the impact of TBI on themselves and their family was discussed in Whiffin et al (2015). However, the aim of this paper is to describe the narrative structures used by the uninjured members of a family to understand change. These changes naturally centred around the injured person and therefore relate primarily, to their perspective of whether and how the injured person had changed. However, this study also examined whether and why they themselves felt they had changed in the first year post-TBI. 


\section{METHODS}

\section{Participants}

All participants were family members of a relative who had sustained a TBI with admission to neurointensive care. Family members were approached to take part in this study once their relative had been discharged to a ward environment. Following ethical approval by the NHS research ethics committee (REC Reference Number:

08/H0308/181) nine uninjured family members from three families consented to join this study. Of those approached to join the study only one family was unable to participate because this research required at least two members of the same family and in this instance, only one family member wanted to participate. In addition, one member of case two (described below) withdrew before the final interview. It is hard to speculate on the differences between those who did participate, and those who did not. It is possible these families were significantly more or less distressed than those included.

The three families are presented as cases and described below (all names and identifying characteristics have been changed).

Case one: Dave aged 58. The participating family members were Suzanne (spouse) aged 36 and Emma (adult daughter and stepdaughter to Suzanne) aged 27. The injury was caused by a fall of six/seven metres; it was unknown how long it was until he was found. Dave sustained a severe TBI, fractured base of skull, cerebral oedema and a fractured leg. Following admission to neuro-critical care, he was intubated and sedated for approximately ten days. Subsequently, he was transferred to a specialist neurological ward and assessed for rehabilitation but no beds were available, he then self-discharged at one-month post-injury. 
Case two: Abigail aged 19. The participating family members were Diane (mother) aged 54, Bill (father) aged 55 and Lucy (older sibling) aged 22. Abigail was involved in a road traffic accident as a pedestrian and sustained a severe TBI with a fractured skull and fractured leg. Following neuro-surgery, she was admitted to neurocritical care intubated and sedated until well enough to be admitted to a specialist neurological ward and finally discharged home just over one-month post-injury.

Case three: Tracey aged 26. The participating family members were Mike (spouse) aged 29, Kate (mother) aged 54, Peter (father) aged 54, and Helen (older sibling) aged 27. Tracey was in a road traffic accident sustaining a severe TBI, diffuse axonal injury, intracranial haemorrhage and cerebral oedema requiring admission to neuro-critical care to be intubated and sedated. One month after injury Tracey was well enough to be transferred to a specialist neurological ward and later had a period of inpatient rehabilitation. Approximately three-months post-injury Tracey was discharged home.

At one year post-injury, all injured persons had resumed most activities of daily living, including a return to work, with some minor residual deficits apparent. Such an outcome would be classified by the Glasgow Outcome Score as a 'good recovery' (Jennett \& Bond, 1975).

\section{Design}

This study used social constructivism and narrative theory as its conceptual framework. The social constructivist paradigm views reality as relative to those experiencing it and proposes that experience is created, shaped and constructed through social interaction and individual interpretation (Denzin \& Lincoln, 2011). The assumption, therefore, is that the experience of being in the world is never singular or objective. Within research 
this allows several different perspectives to be examined so that a deeper understanding can be reached about how individuals make sense of their experiences. The priorities of the constructivist paradigm align to those of narrative theory and Sparkes and Smith (2008) explain these are commonly used together.

Narrative traditions view people as innate story tellers and when faced with a disruption to normal daily life stories about this event are created (Bingley, Thomas, Brown, Reeve, \& Payne, 2008). Stories are therefore important at times of transition or change and are viewed as instruments to make sense of events that reshape our lives. The way these narratives are crafted reveals something about the meaning attributed to them (Bruner, 1990). In Acts of Meaning, Jerome Bruner called for the field of psychology to return to more human concerns of meaning making and its importance to 'being in the world'. Bruner (1990) stated 'I have been at great pains to argue [...] that one of the most ubiquitous and powerful discourse forms in human communication is narrative’ (p77).

\section{Procedure}

Participants completed three unstructured narrative interviews: one, three and twelve months post-injury. Narrative interviews are an open form of interview designed around what the participants wish to talk about. Wengraf and Chamberlayne (2006) devised a structure for narrative interviews which comprises three stages: Stage One: invite the participant to talk about their experience; Stage Two, ask follow-up questions based on their response, and Stage Three, ask additional questions based on issues that have not already been discussed. All interviews were conducted by the first author (CW) and participants were asked to choose an appropriate location. Subsequently, the interviews were completed either at the hospital (in a research facility), their place of 
work or in their own home. Twenty-six interviews were conducted (one participant withdrew prior to the final interview). Interviews lasted on average 90 minutes (range between 40 and 137 minutes).

\section{Data analysis}

Interviews were transcribed by the first author (CW) into a Word document. Interviews were listened to several times and transcripts were then read and re-read. An in-depth narrative analysis was then conducted. Approaches to narrative inquiry include specific research strategies that consider how the retelling of events and experiences can reveal more about the experience than simply identifying a factual account (Bingley et al., 2008). In this narrative form, the story is not broken into small pieces or fragmented into thematic categories. Instead, the textual data collected are treated more holistically and attempts are made to reconstruct a whole story (Riessman \& Quinney, 2005). Therefore during the analysis participants' accounts were 're-storied' into a format that would allow chronology, context and causal links to be revealed (Creswell, 2013). This process allowed life before, life now and life after to be illuminated. This temporality is a hallmark of narrative inquiry and reveals how people have made sense of events they have experienced.

The analysis then continued to move beyond the re-storied account towards something more meaningful. This interpretation was heavily influenced by the Life Thread Model which conceptualises the whole as comprising a number of narrative threads (Ellis-Hill et al., 2008). The analysis was conducted at three levels: 1. exploring the structures of individual narratives; 2 . how these linked with the narratives of other members of the same family; and 3. how the three overall family narrative structures were similar or different to each other. Although the first author (CW) was responsible 
for the primary analysis of data all authors contributed to the interpretation of data and agreed on final findings. For a detailed discussion of data analysis procedures please see Whiffin (2012) and Whiffin, Bailey, Ellis-Hill, and Jarrett (2014).

The writings of Bury (1982), G Williams (1984), and S J Williams (2000), were particularly influential in identifying the final narrative structures in this study. Narrative structures refer to the order we assign to the stories we tell about our lives. Through these structures, the meaning of the story is conveyed and illustrates to others how events in our lives have been made sense of. Following data analysis, four narrative structures were identified in this study: biographical attendance; biographical disruption; biographical continuity and biographical reconstruction.

Biographical attendance was defined during this research as a process of using narratives to maintain the injured person's identity at times when the person was unable to fully express it themselves. This is a new narrative structure that is yet to be discussed in the literature.

Biographical disruption is a process by which people reconsider who they think they are, and will be in the future. Bury (1982) used biographical disruption to describe how people viewed themselves in the context of a long-term illness. Such illness had 'disrupted' their sense of self and for some disconnected them from their anticipated future. This concept aligns well to TBI if we are to believe that change post-injury can disrupt the present and future concept of self. However, 'disruption’ suggests change can only occur in one direction.

Biographical continuity, on the other hand, refers to the narratives that are not threatened in the presence of illness and the person is not disconnected from their prior self. Therefore this narrative structure sits in direct contrast to biographical disruption and explicitly challenges this discourse of loss (S. J. Williams, 2000). Finally, 
biographical reconstruction is defined as an attempt to realign narrative order by revising our self-concept in the past, present and future (G. Williams, 1984).

\section{RESULTS}

Data that referred directly to the recovery of the injured relative revealed how the uninjured family members understood identity and change. The findings showed that family members had a lot of narrative work to do post-injury; which means they needed to understand their own sense of self post-injury as well as making sense of the identity and character of their injured relative. It is this narrative understanding of change that is the focus of this paper.

Examples of the four narrative structures are presented below starting with biographical attendance, then moving on to biographical disruption, biographical continuity, and finally biographical reconstruction, which is used to examine how family members’ own identities are challenged alongside that of the injured person. During this discussion, the consequences of biographical reconstruction when not all family members share the same experience is discussed in terms of 'narrative misalignment'. Narrative misalignment is defined as a lack of symmetry between people, events and experiences and the impact this has on their interpretation. Extracts of data are presented below from family members that illustrate these narrative structures and the context in which family members were speaking.

\section{Biographical Attendance}

Biographical attendance was especially noticeable within the early accounts and during periods of unconsciousness and confusion. Often the need to attend to the injured person's identity was a direct consequence of being told by health professionals that the injured person would no longer be the same. Biographical attendance involved family 
members actively looking for, and describing known character traits. Recognisable personality traits that were important to the uninjured family member were then shared with the family or others, including healthcare staff.

Suzanne noticed physical cues: 'When he first woke up... I could see that... even when he was asleep, the way he was putting his hands... and I thought... oh... yes, you know, that's him...' (First interview)

Emma noticed and shared how her father spoke: 'he'd say 'yes, yes, boss, yes Fraulein'... and he'd say that to everyone and it was like yes well that's the kind of thing he says, and that was such a relief...' (First interview)

Lucy used biographical attendance with a family member and recalled her sister's character: ‘And my dad... [laughs]... he’s so blunt... 'oh I just don't want her to be a vegetable' [laughs] and I was like... 'dad... you can't, firstly say that and secondly, she won't'... and I had this... eternal feeling that she wouldn't, my sister's so flipping... feisty and such $a . .$. stubborn mule... I couldn't ever see that leaving her... she'd just be like 'no, I'm not gonna give in to you lot'...' (First interview)

The process of biographical attendance helped family members in this study to make a connection to the injured person as the person they were before the injury. As such, these acts helped to create positive affirmations of the future and represented the possibility for recovery even when the outcome was unknown. 


\section{Biographical disruption}

Almost all family members talked about the possibility that their relative could be different from the person they were prior to injury. This change was either predicted by healthcare professionals in their professional discourse or was a consequence of TBI of which family members were already aware.

Suzanne predicted the consequence of biographical disruption: '... I was really worried that he would not be him at all... that was one of my worst fears, that you know if he's not like his old good self, will I still love him, and will he still love us? Will he remember what we've been through?' (First interview)

Emma tried to make sense of the medical view: 'He [doctor] was like 'oh but his personality might be affected'...and I was like 'well...that's quite a big deal!' [laughs]...you know, 'here’s your dad by the way he's not actually your dad 'cause he's completely different to the person he was before'...' (First interview)

For some this threat was purely hypothetical and was not realised in the year this study was conducted. For others, possible changes were examined and explored during their portrayal of their relative’s recovery journey.

Suzanne spoke about what was different post-injury: '...that's when we sort of find that... under stress, he doesn't cope as well as before... because he's sort of a calm person and... he would just deal with it really well... I think now he just gets really vocal and... sometimes if you walk into his office and you say something he just... BURST... or he snaps or he slams or he... breaks or... that's something that he never used to do before...' (Third interview)

However, these changes were not always as catastrophic as they had been led to believe 
but they could still be significant.

Lucy found humour in the changes she identified: 'she [Mother] came in, in the morning and said to me 'Lucy you need to do lunch for about two' ... and Abigail comes down stairs and goes 'What's this... you're cooking lunch for just you and Mum'... and I was like... no Abigail not for two of us ... for two o'clock! ... and she went 'oh yeah! oh yeah! ... [laughs]... (Second interview)

Diane showed how changes were sometimes unquantifiable: 'I've said to Abigail before you know... do you think this is what you were like before or... is this something, 'oh yes[!] she says, it was probably what I was like beforehand'...... [long pause]... she was worried she was going to wash away on holiday [said very quietly]... she'd got a li-lo... and I said to her she could sunbathe in the water... the beach we'd gone to was really calm... [but] she thought she might wash away...' (Third interview)

There was evidence that family members still had a strong sense that TBI can fundamentally change the injured person and one year after injury Suzanne illustrated her perception of her husband's biographical disruption by describing him as 'a shell that you're used to but something on the inside was different'.

\section{Biographical continuity}

Juxtaposed to the narratives of biographical disruption were narratives of biographical continuity. S J Williams (2000) argued that in some circumstances illness does not result in a biographical shift, and suggests that continuity not change is the dominant discourse. Such continuity relies on elements of biographical confirmation and 
reinforcement. This study found that despite the medical discourse preparing families for change there were circumstances where change was not a dominant feature of all the accounts.

Helen wanted to affirm her sister’s biographical continuity: 'I remember when she first came out and she'd come into town with my mum sometimes... and they'd pop in to see me here [at work] and I'd run around the office with her going 'look, look at her'... [laughs]... like she was some like show and tell...' [Third interview]

Kate compared the real to the hypothetical to emphasise biographical continuity: 'And course she's come home and she's come on leaps and bounds... it's a miracle on two legs really... I mean everybody... all the doctors she speaks to they're all amazed how well she's doing ... and when you think where we were and where she is now I mean, she's talking about going back to work now... I mean... it just doesn't seem possible...' [Second interview]

Peter revealed that biographical continuity was identified early: 'Once she woke up and started talking she was almost instantly back to her normal self although she was obviously sort of... you know only just capable of talking... her manner and the way she's talking and speaking to people... it hasn't changed... it was wonderful to know it was our Tracey that was back and not... a half something of a Tracey that was back...'(Second interview)

Return to a pre-injury self was considered a key milestone in the injured person's journey and this narrative of biographical continuity was used by family members to illustrate recovery had been reached. 


\section{Biographical reconstruction of self and others}

G Williams (1984) argued that in the presence of chronic illness individuals re-examine their changing relationship to the world. As such illness does not necessarily 'disrupt' a sense of self, but it may force a reconstruction of a sense of self if the taken for granted world is threatened. 'Narrative reconstruction is an attempt to reconstitute and repair ruptures between body, self, and world by linking-up and interpreting different aspects of biography in order to realign present and past and self with society' (G Williams, 1984 p.197). In this study, the uninjured family members all faced a threat to their taken for granted future in the wake of the critical illness of a relative. These uninjured family members experienced deep trauma and clearly articulated their acute and distressing pain through stories of fear, helplessness, and horror.

Bill described the scene of his daughter's accident: 'I don't know what you think, just didn’t really, you don't imagine I suppose, not having seen her on the road... saw where her shoes were, or one of them in particular ... your just sort of, numb...you see lots of stuff lying around.... and you've got people telling you "it was awful” (First interview)

Emma talked about reading an entry in the relative’s book in intensive care written by her younger stepsister: '...'dear Daddy... I'm sorry I didn't go with you the day of your accident... if I was there I could have called for help'... she was feeling really guilty and that was horrible to read that...' (First interview)

Not knowing if their relative would live or die was further complicated by not knowing if the head injury would still rob them of the person they knew prior to injury once survival was assured. Families were fully immersed in this acute experience and were alongside other families experiencing similar grief and loss. 
Bill described living day to day in intensive care: 'and we'd already had the anguish of some of the other people that were in the unit where ... it would seem that some of them had just been recently turned off who weren't gonna make it anymore or weren't surviving...(First interview)

Peter talked about an early consultation where it was suggested his daughter might be in a vegetative state: 'And just that one word... vegetative state... and you thought... oh hell... and we looked at each other... and your heart sank without a doubt... have we got her life saved to be a vegetable... and you think god... what have we done... has technology condemned her to... something worse than hell' (First interview)

Despite all those with injuries surviving and returning home the pain of the experience did not always diminish over time. Some family members talked of their continued suffering, often from an accumulation of subjective losses.

Suzanne showed how over time her experience had got progressively worse: ' $I$ think just around Easter time when he was being... really sort of er... difficult, you know I had a breakdown at work... you know I was crying... and that's never happened before... it's like 'oh Suzanne are you alright, do want to take time off'... oh dear... just one day I just couldn't do it...' (Third interview)

Diane talked about the burden of holding the family together: 'I think the mother carries all the burden don't they, I think in old families, I think even now... [tearful]... the mother holds it together for the family... if I don't hold it together... or... keep normality going then... who's going to do it?' (Third interview)

As a result of the trauma and suffering uninjured family members found themselves trying to make sense of how their own life had been changed by their experience of TBI. Loss of their anticipated future, for themselves or others, revised their sense of self and 
the family unit changed within this new context where the future was unknown. Importantly however, these revisions often occurred without the knowledge and understanding of the injured person because they themselves had not been conscious during this early trauma. In addition, the injured member was not always thought to be fully aware of what had been lost. Therefore, these revisions had the added complication of making the injured person an outsider to this experience.

Emma talked about the change evident in herself and others: '...it's brought me and Suzanne and the girls really close together... but if anything, my Dad's been a bit left out on that 'cause... [laughs] ... he was just asleep for a few weeks and wakes up! [laughs]... it feels like we had a crisis and he wasn't around and we dealt with it... but he's not kind of benefited from all the bonding that's gone on!' (First interview)

In addition to the biographical reconstruction of the uninjured family members sense of self, family members also spoke about how they could assist the injured person to reconstruct their own identify in the wake of TBI.

Diane tried to reconnect her daughter to her ambitions pre-injury: 'But she might have to change what she was planning to do... but what she was doing is what she's always wanted to do since she was about three...it will come hard for her to be told that, say 'that isn't going to be her option anymore'... she may have to re-think...... so I don't know...[pause] ... it's difficult... (First interview)

In the above example, the uninjured family members remembered the importance of Abigail's past biography, more than they felt Abigail herself did. It was clear that these ambitions were also an important part of the family's identity. This emphasised the 
interconnected nature of narratives between all injured and uninjured family members and the potential for misalignment in the future.

\section{Biographical misalignment}

Most commonly in narrative research, the individual's story is preserved and prioritised. However, this study considered both the individual's story and how this was understood within a family context. What the data suggested was that the symmetry between narratives in families was important. Where events and experiences were shared and subsequent narratives created were similar, or aligned, family members felt closer, united, and pulled inwards. However, the term narrative misalignment was used to describe the consequences of sharing physical spaces, events and experiences but developing differing interpretations of these. The consequences of this misalignment were feelings of isolation within families. These misaligned narratives emphasised the division within families and illustrated how the family could be pulling apart.

Mike revealed how he thought his wife would always be a step removed from their experiences as a family: 'even though she was awake she was probably still in some sort of a coma... and that's quite strange because... the experiences that... we had together with her awake... she can't remember... it's really, really odd, it's almost as if there was another life running alongside... that she had no part of... and ultimately she lost... two or three months of her life... but she was there... and we've all got very vivid memories of it...'(Third interview)

Emma described how not sharing her stepmother's experience was leaving Suzanne feeling vulnerable and isolated: '... so I think that was quite horrible for Suzanne and then these changes in temper and mood and short fuses that she's told me about... if no one else witnesses it or... no one else sees it... that 
must be pretty tough...' (Third interview)

\section{DISCUSSION}

The findings revealed how biographical attendance, biographical disruption,

biographical continuity and biographical reconstruction can help to understand why and how families are so affected by TBI. The data revealed complex and interwoven processes in understanding change post-TBI for the whole family. The findings also showed how narrative misalignment creates distance between its members which can undermine cohesion within families. Such narratives have great potential to increase understanding of outcome for patients and families over and above objective measures.

In a meta-synthesis of TBI research, loss and reconstruction of self-identity and personhood were common themes post-TBI (Levack, Kayes, \& Fadyl, 2010). In a grounded theory study of ten individuals who had sustained a TBI Nochi (1998) concluded that individuals fundamentally revised their 'self-narrative by changing the appearance of their past and future’ (p.1797). More recently Abrahamson et al. (2016) interviewed 41 brain injured individuals and their family members and identified a ‘disintegration of self-identity’ and understanding that life post-injury would be very different. Furthermore, Muenchberger et al. (2008) examined identity transition in six individuals with TBI and described TBI as a dynamic journey with a constant interplay between pre-and-post injury comparisons, and while there were negative outcomes there were also positives to be taken from the experience. This research reflects a growing interest in self-concept following TBI (Gracey \& Ownsworth, 2012; Ownsworth \& Haslam, 2016) and the findings of this study resonate with this literature.

However, only a small number of studies consider how uninjured family members contribute to the understanding of loss and change following TBI 
(Abrahamson et al., 2016; Couchman et al., 2014). By exploring biographical attendance, disruption, continuity and reconstruction in the context of TBI this study adds to the literature on self-concept by proposing a different way to think about change post-injury. It is suggested that identity change in a narrative sense is how we learn to understand ourselves in the world and the sort of worlds we create. Galvin and Todres (2012) suggest that using this lifeworld approach allows service providers to support people to feel valued as whole human beings.

Although this research was completed with uninjured family members and not the injured person it shows the complexity of change post-injury and that family members are active agents in this process. Where families provide the main social and support networks for injured persons it is reasonable to assume that narratives of the uninjured members influence how the injured person makes sense of the events they have experienced post-injury. However, this assumption needs testing in future research.

Narrative alignment in families was examined and it was found that narrative misalignment can be painful and may mean families find it hard to stay together because they are living different realities. Not sharing realities may lead to individuals feeling they are isolated from the rest of the family. Figure 1 illustrates the narrative alignment of families pre-injury, making an assumption that families have a shared sense of narrative order, and suggests the injured member moves out of the shared narrative during illness. The findings of this study resonate with those by Couchman et al. (2014) who found in a population of individuals with acquired brain injuries that 'conflicts and gulfs' between members (p.823) damaged family relationships. This feeling of misalignment of past, present and future may contribute to intangible and ambiguous losses that have been reported post-TBI (Abrahamson et al., 2016; Kreutzer 
et al., 2016). Further research is required to understand narrative alignment pre-injury and how families help to preserve, sustain or realign narrative order for the whole family post-injury.

Ellis-Hill et al. (2008) argue that in rehabilitation following stroke physical recovery is prioritised above social and emotional domains. In a similar way, traditional rehabilitation following TBI concentrates on impairment and ability or activity and social participation in isolation from each other (Gracey et al., 2008). In contrast, EllisHill et al. (2008) suggest that the Life Thread Model could enhance current practice and research. The Life Thread Model represents the stories, or strands, of our everyday selves. In an intact thread, our past, present and future lives are connected and this connection/continuity grounds our sense of self. Continuity is essential for wellbeing but illness or injury can displace continuity as the future becomes disconnected from the past and present. In the Life Thread Model, this is represented by threads breaking and fraying. In contrast to a model of loss, life threads enable us to see ourselves as comprised of a number of different stories. In the presence of disability, some threads may inevitably need to be tied off. However, positive approaches to rehabilitation will find ways to reconnect these threads thereby increasing the individual's positive sense of self. In addition, it is also important to understand the threads that were never broken by illness and enable the individual to see what has not been lost.

In the context of this study, the Life Thread Model can help to further understand family members' narratives. Biographical attendance can be viewed as family members holding together the frayed threads that look like they may break in the wake of TBI. Family members are usually the first to recognise when threads do break and this is understood as a form of biographical disruption. Biographical reconstruction then helps to understand how family members themselves are changing following TBI 
and also how they help to sustain the self-concept of the injured person. Family members also have a role in biographical continuity by recognising threads from the past and present that remain connected to the future. In this context, family members can be considered 'guardians of self-concept' during periods of biographical attendance, and then active agents in the process of biographical disruption, continuity and reconstruction. Recognising and working with these positive representations may allow healthcare practitioners to learn about the meanings created by the person and their family and allow collaborative ways of working with the whole family.

\section{LIMITATIONS}

Despite the fact that this was a small study of three families and therefore is not generalisable, the communicative power of this research lies in the comprehensive analysis of three interviews with nine family members resulting in an in-depth examination of family context that would not be achieved with a larger more representative sample size. It could also be argued that asking individuals to compare their present self with their past self may result in an idealisation of their pre-injury self (Ponsford, Kelly, \& Couchman, 2014). However, narratives do not have to be accurate representations of what took place (Carter, 2008), because they are accurate representations of how the teller has made sense of what took place. As such it is the process of identifying cause and meaning that is important.

\section{CONCLUSION}

In this paper, it was argued that change is not a one-dimensional concept, nor is it static or should be viewed as an end point in the journey of recovery post-injury. Four narrative structures, biographical attendance, disruption, continuity and reconstruction of self and others, were found to be key aspects of the experience of family members 
post-TBI, and indications that change is a multifaceted concept. Narrow characterisations of this experience as a form of loss may be unhelpful and dehumanising. It is therefore proposed that there be a shift in the discourse in research and practice literature away from loss and towards transition, with greater recognition of the role that uninjured family members play in making sense of change post-injury.

Family members are too frequently treated as witnesses to the illness journey rather than as people embarking on a journey of their own. However, this study has shown that family members do embark on their own journey, that they themselves are changing as a result of injury and that they are also active agents in making sense of 'self-concept' for the injured person. It is also important to recognise that often families may experience a form of misalignment post-injury and that ways of helping families to realign and reconstruct themselves post-injury may be a helpful strategy for rehabilitation. Future research should examine how families help to preserve, sustain or realign narrative order both for themselves and the whole family. Understanding how healthcare practitioners can support families to reconstruct their identities in a meaningful way post injury should be prioritised.

\section{Declaration of Interest}

No conflict of interest is declared

\section{Acknowledgements}

PJH is supported by a NIHR Research Professorship and the NIHR Cambridge BRC The Wellcome Trust Clinical Research Facility 


\section{REFERENCES}

Abrahamson, V., Jensen, J., Springett, K., \& Sakel, M. (2016). Experiences of patients with traumatic brain injury and their carers during transition from in-patient rehabilitation to the community: a qualitative study. Disability and Rehabilitation, 1-12. https://doi.org/10.1080/09638288.2016.1211755

Anderson, M. I., Parmenter, T. R., \& Mok, M. (2002). The relationship between neurobehavioural problems of severe traumatic brain injury (TBI), family functioning and the psychological well-being of the spouse/caregiver: path model analysis. Brain Injury, 16(9), 743-57. https://doi.org/10.1080/02699050210128906

Bingley, A. F., Thomas, C., Brown, J., Reeve, J., \& Payne, S. (2008). Developing narrative research in supportive and palliative care: the focus on illness narratives. Palliative Medicine, 22(5), 653-658. https://doi.org/10.1177/0269216308089842

Blake, H. (2008). Caregiver stress in traumatic brain injury. International Journal of Therapy \& Rehabilitation, 15(6), 263-271 9p. https://doi.org/10.12968/ijtr.2008.15.6.29878

Bowen, C., Hall, T., Newby, G., Walsh, B., Weatherhead, B., \& Yeates, G. N. (2009). The Impact of Brain Injury on Relationships Across the Lifespan and Across School, Family and Work Contexts. Human Systems: The Journal of Therapy, Consultation and training.2, 20(1), 62-77.

Bruner, J. (1990). Acts of meaning. Cambridge, Mass: Harvard University. Bury, M. (1982). Chronic illness as biographical disruption. Sociology of Health \& Illness, 4(2), 167-182. https://doi.org/10.1111/1467-9566.ep11339939

Butera-Prinzi, F., \& Perlesz, A. (2004). Through children’s eyes: children’s experience of living with a parent with an acquired brain injury. Brain Injury, 18(1), 83-101. https://doi.org/10.1080/0269905031000118500 
Carnes, S. L., \& Quinn, W. H. (2005). Family Adaptation to Brain Injury: Coping and Psychological Distress. Families, Systems, \& Health, 23(2), 186-203. https://doi.org/10.1037/1091-7527.23.2.186

Carter, B. (2008). “Good” and “bad” stories: Decisive moments, “shock and awe” and being moral. Journal of Clinical Nursing, 17(8), 1063-1070. https://doi.org/10.1111/j.1365-2702.2006.01942.x

Connolly, D., \& O’Dowd, T. (2001). The impact of the different disabilities arising from head injury on the primary caregiver. British Journal of Occupational Therapy, 64(1), 41-46.

Couchman, G., McMahon, G., Kelly, A., \& Ponsford, J. (2014). A new kind of normal: qualitative accounts of Multifamily Group Therapy for acquired brain injury. Neuropsychological Rehabilitation, 24(6), 809-832. https://doi.org/10.1080/09602011.2014.912957

Creswell, J. W. (2013). Research design: qualitative, quantitative, and mixed method approaches, Fourth edition, international student edition. Los Angeles, Calif: SAGE. Retrieved from http://capitadiscovery.co.uk/derby-ac/items/991688

Degeneffe, C. E. (2001). Family caregiving and traumatic brain injury. Health Soc Work, 26(4), 257-268. Retrieved from http://www.ncbi.nlm.nih.gov/pubmed/11758867

Degeneffe, C. E., \& Burcham, C. M. (2008). Adult sibling caregiving for persons with traumatic brain injury: Predictors of affective and instrument support. Journal of Rehabilitation, 74(3), 10-20.

Degeneffe, C. E., \& Lee, G. K. (2010). Quality of life after traumatic brain injury: Perspectives of adult siblings. Journal of Rehabilitation, 76(4), 27-36.

Degeneffe, C. E., \& Lynch, R. T. (2006). Correlates of depression in adult siblings of 
persons with traumatic brain injury. Rehabilitation Counseling Bulletin, 49(3), $130-187$.

Degeneffe, C. E., \& Olney, M. F. (2008). Future concerns of adult siblings of persons with traumatic brain injury. Rehabilitation Counseling Bulletin, 51(4), 240-250. Retrieved from http://search.ebscohost.com/login.aspx?direct=true\&db=cin20\&AN=2010041747 \&site=ehost-live

Degeneffe, C. E., \& Olney, M. F. (2010). "We are the forgotten victims”: Perspectives of adult siblings of persons with traumatic brain injury. Brain Injury, 24(12), 1416-1427. https://doi.org/10.3109/02699052.2010.514317

Denzin, N. K., \& Lincoln, Y. S. (2011). The Sage Handbook of Qualitative Research (4th ed.). Thousand Oaks: Sage.

Ellis-Hill, C., Payne, S., \& Ward, C. (2008). Using stroke to explore the life thread model: an alternative approach to understanding rehabilitation following an acquired disability. Disability and Rehabilitation, 30(2), 150-159. https://doi.org/10.1080/09638280701195462

Foster, A. M., Armstrong, J., Buckley, A., Sherry, J., Young, T., Foliaki, S., ... McPherson, K. M. (2012). Encouraging family engagement in the rehabilitation process: a rehabilitation provider's development of support strategies for family members of people with traumatic brain injury. Disability and Rehabilitation, 34(22), 1855-62. https://doi.org/10.3109/09638288.2012.670028

Galvin, K., \& Todres, L. (2012). Caring and Well-being: A Lifeworld Approach. London: Routledge.

Gan, C., Campbell, K. A., Gemeinhardt, M., \& McFadden, G. T. (2006). Predictors of family system functioning after brain injury. Brain Injury, 20(6), 587-600. 
https://doi.org/10.1080/02699050600743725

Gervasio, A. H., \& Kreutzer, J. S. (1997). Kinship and Family Members’ Psychological Distress after Traumatic Brain Injury: A Large Sample Study. The Journal of Head Trauma Rehabilitation, 12(3). Retrieved from http://journals.lww.com/headtraumarehab/Fulltext/1997/06000/Kinship_and_Famil y_Members_Psychological_Distress.3.aspx

Gill, C. J., Sander, A. M., Robins, N., Mazzei, D. K., \& Struchen, M. A. (2011). Exploring Experiences of Intimacy From the Viewpoint of Individuals With Traumatic Brain Injury and Their Partners. Journal of Head Trauma Rehabilitation, 26(1), 56-68. https://doi.org/10.1097/HTR.0b013e3182048ee9

Gill, D. J., \& Wells, D. L. (2000). Forever different: experiences of living with a sibling who has a traumatic brain injury. Rehabilitation Nursing, 25(2), 48-79.

Gosling, J., \& Oddy, M. (1999). Rearranged marriages: marital relationships after head injury. Brain Injury, 13(10), 785-796. https://doi.org/10.1080/026990599121179

Gracey, F., \& Ownsworth, T. (2012). The experience of self in the world: The personal and social contexts of identity change after brain injury. In J. Jetten, C. Haslam, \& A. Haslam (Eds.), The Social Cure (pp. 273-295). Hove: Psychology Press. https://doi.org/10.4324/9780203813195

Gracey, F., Palmer, S., Rous, B., Psaila, K., Shaw, K., O’Dell, J., ... Mohamed, S. (2008). “Feeling part of things": personal construction of self after brain injury. Neuropsychological Rehabilitation, 18(December), 627-650. https://doi.org/10.1080/09602010802041238

Hammond, F. M., Davis, C. S., Whiteside, O. Y., Philbrick, P., \& Hirsch, M. A. (2011). Marital adjustment and stability following traumatic brain injury: a pilot qualitative analysis of spouse perspectives. The Journal of Head Trauma Rehabilitation, 
26(1), 69-78. https://doi.org/10.1097/HTR.0b013e318205174d

Harris, D., \& Stuart, A. D. (2006). Adolescents' experience of a parental traumatic brain injury. Health SA Gesondheid, 11(4), 46-56.

Harris, J. K. J., Godfrey, H. P. D., Partridge, F. M., \& Knight, R. G. (2001). Caregiver depression following traumatic brain injury (TBI): a consequence of adverse effects on family members? Brain Injury, 15(3), 223-238.

https://doi.org/10.1080/02699050010004040

Holloway, I., \& Freshwater, D. (2007). Narrative Research in Nursing. Oxford: Blackwell Publishers.

Jackson, D., Turner-Stokes, L., Murray, J., Leese, M., \& McPherson, K. M. (2009). Acquired brain injury and dementia: A comparison of carer experiences. Brain Injury, 23(5), 433-444. https://doi.org/10.1080/02699050902788451

Jennett, B., \& Bond, M. (1975). Assessment of outcome after severe brain damage. Lancet, 1(7905), 480.

Jumisko, E., Lexell, J., \& Soderberg, S. (2007). Living with moderate or severe traumatic brain injury: the meaning of family members' experiences. Journal of Family Nursing, 13(3), 353-369. https://doi.org/10.1177/1074840707303842

Kieffer-Kristensen, R., Teasdale, T. W., \& Bilenberg, N. (2011). Post-traumatic stress symptoms and psychological functioning in children of parents with acquired brain injury. Brain Injury, 25(7-8), 752-760. https://doi.org/10.3109/02699052.2011.579933

Kosciulek, J. F. (1997). Relationship of family schema to family adaptation to brain injury. Brain Injury, 11(11), 821-30. https://doi.org/10.1080/026990597123034 Kreutzer, J. S., Marwitz, J. H., Hsu, N., Williams, K., \& Riddick, A. (2007). Marital stability after brain injury: an investigation and analysis. NeuroRehabilitation, 
22(1), 53-9.

Kreutzer, J. S., Mills, A., \& Marwitz, J. H. (2016). Ambiguous Loss and Emotional Recovery After Traumatic Brain Injury. Journal of Family Theory and Review, 8(3), 386-397. https://doi.org/10.1111/jftr.12150

Levack, W. M. M., Kayes, N. M., \& Fadyl, J. K. (2010). Experience of recovery and outcome following traumatic brain injury: A metasynthesis of qualitative research. Disability and Rehabilitation, 32(March), 986-999. https://doi.org/10.3109/09638281003775394

McCubin, M. A., \& McCubin, H. I. (1991). Family stress theory and assessment: the Resiliency Model of family stress, adjustment, and adaptation. In H. I. McCubbin \& A. I. Thompson (Eds.), Family assessment inventories for research and practice (2nd ed., pp. 3-32). Madison, Wisconsin: University of Wisconsin-Madison.

Muenchberger, H., Kendall, E., \& Neal, R. (2008). Identity transition following traumatic brain injury: a dynamic process of contraction, expansion and tentative balance. Brain Injury, 22(12), 979-992. https://doi.org/10.1080/02699050802530532

Nabors, N., Seacat, J., \& Rosenthal, M. (2002). Predictors of caregiver burden following traumatic brain injury. Brain Injury, 16(12), 1039-1050. https://doi.org/10.1080/02699050210155285

National Institute for Care and Clinical Excellence. (2014). Head injury: assessment and early management. Retrieved January 31, 2017, from https://www.nice.org.uk/guidance/cg176/resources/head-injury-assessment-andearly-management-35109755592901

Nochi, M. (1998). "Loss of self” in the narratives of people with traumatic brain injuries: a qualitative analysis. Social Science \& Medicine, 46(7), 869-878. 
https://doi.org/10.1016/S0277-9536(97)00211-6

Orsillo, S. M., McCaffrey, R. J., \& Fisher, J. M. (1993). Siblings of head-injured individuals: A population at risk. The Journal of Head Trauma Rehabilitation, $8(1)$

Ownsworth, T., \& Haslam, C. (2016). Impact of rehabilitation on self-concept following traumatic brain injury: An exploratory systematic review of intervention methodology and efficacy. Neuropsychological Rehabilitation, 2011(November), 1-35. https://doi.org/10.1080/09602011.2014.977924

Perlesz, A., Kinsella, G., \& Crowe, S. (1999). Impact of traumatic brain injury on the family: A critical review. Rehabilitation Psychology, 44(1), 6-35. https://doi.org/10.1037/0090-5550.44.1.6

Perlesz, A., Kinsella, G., \& Crowe, S. (2000). Psychological Distress and Family Satisfaction Following Traumatic Brain Injury: Injured Individuals and Their Primary, Secondary, and Tertiary Carers. Journal of Head Trauma Rehabilitation, 15(3), 909-929. https://doi.org/10.1097/00001199-200006000-00005

Ponsford, J., Kelly, A., \& Couchman, G. (2014). Self-concept and self-esteem after acquired brain injury: A control group comparison. Brain Injury, 28(2), 146-54. https://doi.org/10.3109/02699052.2013.859733

Ponsford, J., Olver, J., Ponsford, M., \& Nelms, R. (2003). Long-term adjustment of families following traumatic brain injury where comprehensive rehabilitation has been provided. Brain Injury, 17(6), 453-468.

https://doi.org/10.1080/0269905031000070143

Riessman, C. K., \& Quinney, L. (2005). Narrative in Social Work: A Critical Review. Qualitative Social Work, 4(4), 391-412. https://doi.org/10.1177/1473325005058643 
Riley, G. A. (2007). Stress and depression in family carers following traumatic brain injury: the influence of beliefs about difficult behaviours. Clinical Rehabilitation, 21(1), 82-88. https://doi.org/10.1177/0269215506071279

Rivera, P. A., Elliott, T. R., Berry, J. W., \& Grant, J. S. (2008). Problem-Solving Training for Family Caregivers of Persons With Traumatic Brain Injuries: A Randomized Controlled Trial. Archives of Physical Medicine and Rehabilitation, 89(5), 931-941. https://doi.org/10.1016/j.apmr.2007.12.032

Sady, M. D., Sander, A. M., Clark, A. N., Sherer, M., Nakase-Richardson, R., \& Malec, J. F. (2010). Relationship of preinjury caregiver and family functioning to community integration in adults with traumatic brain injury. Archives of Physical Medicine and Rehabilitation, 91(10), 1542-1550.

https://doi.org/10.1016/j.apmr.2010.07.012

Sander, A. M., Caroselli, J. S., High, W. M. J., Becker, C., Neese, L., \& Scheibel, R. (2002). Relationship of family functioning to progress in a post-acute rehabilitation programme following traumatic brain injury. Brain Injury, 16(8), 649-657. https://doi.org/10.1080/02699050210128889

Sander, A. M., Sherer, M., Malec, J. F., High, W. M., Thompson, R. N., Moessner, A. M., \& Josey, J. (2003). Preinjury emotional and family functioning in caregivers of persons with traumatic brain injury. Archives of Physical Medicine and Rehabilitation, 84(2), 197-203. https://doi.org/10.1053/apmr.2003.50105

Sparkes, A., \& Smith, B. (2008). Narrative Constructionist Inquiry. In J. Holstein \& J. Gubrium (Eds.), Handbook of Constructionist Research (pp. 295 - 315). New York: Guildford Press.

Verhaeghe, S., Defloor, T., \& Grypdonck, M. (2005). Stress and coping among families of patients with traumatic brain injury: a review of the literature. Journal of 
Clinical Nursing, 14(8), 1004-12. https://doi.org/10.1111/j.1365-

2702.2005.01126.x

Wells, R., Dywan, J., \& Dumas, J. (2005). Life satisfaction and distress in family caregivers as related to specific behavioural changes after traumatic brain injury. Brain Injury, 19(13), 1105-15. https://doi.org/10.1080/02699050500150062

Wengraf, T., \& Chamberlayne, P. (2006). Interviewing for life-histories, lived situations and personal experience: The Biographic-Narrative Interpretive Method (BNIM). Shortest Short Guide to BNIM interviewing and interpretation. Un-published manuscript.

Whiffin, C. J. (2012). A study of family transition in the first year post-head injury: perspectives of the non-injured members. (Unpublished doctoral dissertation). The University of Southampton.

Whiffin, C. J., Bailey, C., Ellis-Hill, C., \& Jarrett, N. (2014). Challenges and solutions during analysis in a longitudinal narrative case study. Nurse Researcher, 21(4), 20-62. https://doi.org/10.7748/nr2014.03.21.4.20.e1238

Whiffin, C. J., Bailey, C., Ellis-Hill, C., Jarrett, N., \& Hutchinson, P. J. (2015). Narratives of family transition during the first year post-head injury: perspectives of the non-injured members. Journal of Advanced Nursing, 71(4), 849-859. https://doi.org/10.1111/jan.12551

Williams, G. (1984). The genesis of chronic illness: narrative re-construction. Sociology of Health \& Illness, 6(2), 175-200. https://doi.org/10.1111/1467-9566.ep10778250

Williams, S. J. (2000). Chronic illness as biographical disruption or biographical disruption as chronic illness? Reflections on a core concept. Sociology of Health \& Illness, 22(1), 40-67. https://doi.org/10.1111/1467-9566.00191

World Health Organisation. (2017). Neurotrauma. Retrieved January 31, 2017, from 
http://www.who.int/violence_injury_prevention/road_traffic/activities/neurotrauma /en/

Yeates, G., Henwood, K., Gracey, F., \& Evans, J. (2007). Awareness of disability after acquired brain injury and the family context. Neuropsychological Rehabilitation, 17(2), 151-173. https://doi.org/10.1080/09602010600696423

Zeigler, E. (1999). Psychosocial issues for spouses of brain injury survivors. The Journal of Neuroscience Nursing : Journal of the American Association of Neuroscience Nurses, 31(2), 106-9. https://doi.org/10.1097/01376517-19990400000007

Figure 1: Narrative Alignment

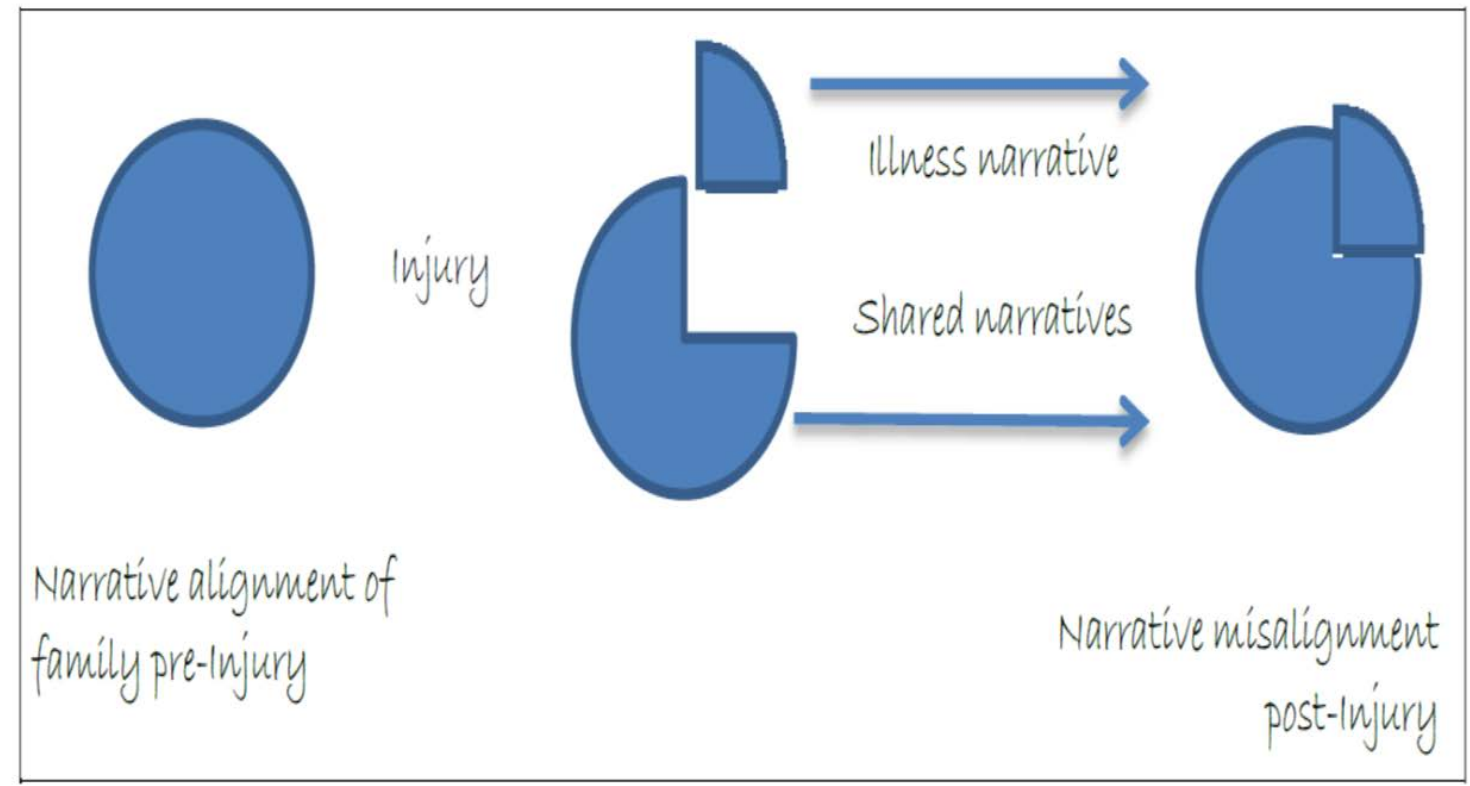

